\title{
Clinical Reasoning: An 18-year-old man with progressive headache and visual loss
}

Nan Jiang, MD, Fei Han, MD, Si-Yuan Fan, MD, Jun Gao, MD, Li-Ying Cui, MD, PhD, Ding-Rong Zhong, MD, * and Bin Peng, MD*

Neurology ${ }^{\circledR}$ 2018;90:1076-1081. doi:10.1212/WNL.0000000000005634
Correspondence

Dr. Peng

pengbin3@hotmail.com

\section{Section 1}

An 18-year-old man presented to the emergency department after 3 weeks of intermittent headaches. He had experienced dull episodic central-parietal pain occurring 1 to 2 times a day and lasting for approximately 1 hour per episode. Headaches were associated with nausea and occasional projectile vomiting when the headaches were severe. He denied aura, photophobia, phonophobia, or blurred vision. Before arriving at the emergency department, he had his first generalized tonic-clonic event for several minutes. He did not have fever or weight loss. His medical and family histories were unremarkable. He denied having recently traveled.

On arrival, the seizure had stopped, and the patient's mental status and vital signs were normal. On physical examination, his optic disc margins were blurred bilaterally. The remainder of the cranial nerve examination was unremarkable. The motor strength, tone, deep tendon reflexes, plantar responses, and sensory examination were normal. His neck was rigid. Systemic examination was unremarkable. A noncontrast enhanced CT scan of the head revealed no abnormalities.

\section{Questions for consideration:}

1. Where would you localize his lesions?

2. What is the differential diagnosis?

\section{GO TO SECTION 2}

\footnotetext{
*These authors contributed equally to this work.
}

From the Departments of Neurology (N.J., F.H., S.-Y.F., L.-Y.C., B.P.), Neurosurgery (J.G.), and Pathology (D.-R.Z.), Peking Union Medical College Hospital, and Neurosciences Center (L.Y.C.), Chinese Academy of Medical Sciences, Beijing.

Go to Neurology.org/N for full disclosures. Funding information and disclosures deemed relevant by the authors, if any, are provided at the end of the article. 


\section{Section 2}

The symptoms of headache, nausea, projectile vomiting, and papilledema could be explained by increased intracranial pressure. Neck stiffness indicates involvement of the meninges, and seizures suggest cortex involvement. The localization common to each of these features is the meningeal space. The patient's history indicated an insidious onset process developing over 3 weeks that strongly suggested chronic meningitis (though some authors prefer waiting 4 weeks before making the distinction between chronic and acute meningitis).

The differential diagnosis of chronic aseptic meningitis is broad (table). In general, patients with chronic meningitis should be asked about travel to or residence in epidemic areas. The immune status should be assessed by history and laboratory testing. Recent medications should be carefully reviewed. Patients with chronic meningitis usually undergo several diagnostic tests, including serology, imaging, and lumbar puncture. Brain or meningeal biopsy may be helpful in patients who have undergone aggressive but ineffective empiric treatment and have progressive deterioration, especially when neuroimaging shows focal findings.
For this patient, routine laboratory tests, including serum screening for rheumatism and vasculitis, serology for HIV and syphilis, and angiotensin-converting enzyme (ACE) level measurement, were normal. A whole-body CT scan did not show any evidence of underlying malignancy. Brain MRI showed diffuse enhancement along the leptomeninges on the surface of the cerebral hemispheres, cerebellum, and brainstem.

On lumbar puncture, the opening pressure was over 400 $\mathrm{mmH}_{2} \mathrm{O}$, and the CSF was xanthochromic. The white cell count was elevated $\left(23 / \mathrm{mm}^{3}\right)$; lymphocytes were predominant. The protein level was $1,400 \mathrm{mg} / \mathrm{dL}$, the CSF glucose level $1 \mathrm{mmol} / \mathrm{L}$, and chloride $108 \mathrm{mmol} / \mathrm{L}$. The CSF acid-fast stain, T-SPOT.TB assay, and India ink stain findings were normal. CSF cultures were negative for bacteria, tuberculosis, and fungi. CSF cytology was negative for malignancy.

\section{Question:}

1. How do auxiliary tests help narrow the differential diagnosis in this case? 
Table Potential causes of chronic aseptic meningitis

\begin{tabular}{|c|c|}
\hline Infections & Noninfectious conditions \\
\hline Viral $^{a}$ & Rheumatic $^{\mathrm{a}}$ \\
\hline HSV II (Mollaret meningitis) and HSV I & Systemic lupus erythematosus \\
\hline Measles & Sjögren syndrome \\
\hline HIV & Behçet disease \\
\hline CMV & Adult-onset Still disease \\
\hline EBV & Granulomatosis with polyangiitis \\
\hline HTLV I and II & Other vasculitides \\
\hline \multicolumn{2}{|l|}{ Enterovirus } \\
\hline \multicolumn{2}{|l|}{ Arboviruses } \\
\hline \multicolumn{2}{|l|}{ vzv } \\
\hline \multicolumn{2}{|l|}{ Mumps } \\
\hline Fungal $^{a}$ & Drug-induced meningitis \\
\hline Cryptococcus & NSAID \\
\hline Histoplasma & IVIg \\
\hline Blastomyces & Allopurinol \\
\hline Coccidioides & Immunosuppressants \\
\hline Candidiasis & Vaccination \\
\hline Sporothrix & Intrathecal agents \\
\hline \multicolumn{2}{|l|}{ Aspergillus } \\
\hline Parasitic & Neoplastic \\
\hline Taenia solium (cysticercosis) & Leptomeningeal carcinomatosis $^{a}$ \\
\hline Angiostrongylus & Leptomeningeal leukemia \\
\hline \multirow[t]{2}{*}{ Schistosoma } & Primary CNS lymphoma \\
\hline & Glioma \\
\hline Protozoa & Neurosarcoidosis $^{a}$ \\
\hline \multicolumn{2}{|l|}{ Toxoplasma } \\
\hline \multicolumn{2}{|l|}{ Acanthamoeba } \\
\hline \multicolumn{2}{|l|}{ Trypanosoma } \\
\hline Brucellosis & Subarachnoid hemorrhage \\
\hline Tuberculosis $^{a}$ & Hypertrophic pachymeningitis \\
\hline Syphilis $^{a}$ & Fabry disease \\
\hline Lyme disease & Cholesterol embolization \\
\hline Leptospirosis & Vogt-Koyanagi-Harada disease \\
\hline \multirow[t]{4}{*}{ Mycoplasma } & Migraine (HaNDL syndrome) \\
\hline & Cryopyrin-associated periodic syndrome \\
\hline & Superficial siderosis \\
\hline & Steroid-responsive chronic idiopathic meningitis \\
\hline
\end{tabular}




\section{Section 3}

In this case, the CSF profile of hypoglycorrhachia, high protein level, and mild mononuclear pleocytosis helped confine the differential diagnosis to tuberculosis, fungi, sarcoidosis, and neoplasms. The serum and CSF screens for tuberculosis and fungi were normal. The absence of fever or apparent immunocompromise did not support obvious infectious causes. The lack of parenchymal mass lesions and systemic findings argued against neoplastic meningitis. Further, the CSF cytology was negative for malignancy. Neither image nor serum ACE screening supported the suspicion of sarcoidosis.

Considering the incidence of tuberculosis in the patient's residence area, and the high morbidity and mortality of tuberculous meningitis if treatment is delayed, we empirically administered antituberculous drugs, as well as mannitol and levetiracetam. After a month's therapy, however, the meningism worsened. Further, the patient's vision gradually declined. Repeated brain MRI revealed ventriculomegaly (figure1A). To control the intracranial pressure, an Ommaya reservoir was implanted for continuous CSF drainage. Prednisone was administered to relieve potential meningeal adhesions. Considering the poor response to antituberculous therapy, empiric antifungals were added for another month. At the end of the third month, the meningism improved, and the patient was discharged. He continued with the antituberculous drugs and prednisone. At the end of the fifth month's follow-up, his vision was below light perception. Because of prolonged bed rest and insufficient rehabilitation, his muscle mass had decreased and his extremities Medical Research Council (MRC) grade was 4+.

On the seventh month, the patient was readmitted because of progressive weakness of all extremities over 1 week. On physical examination, his extremities MRC grade was $0 / 5$. His reflexes were diminished. The Babinski sign was positive bilaterally. Pinprick sensation below the T4 level and vibration sensation of the lower extremities had disappeared. Neck stiffness remained.

\section{Questions:}

1. How do the deteriorating symptoms change the differential diagnosis?

2. What management would help determine the diagnosis?

\section{GO TO SECTION 4}

Figure Brain, spinal cord, and abdominal MRI findings
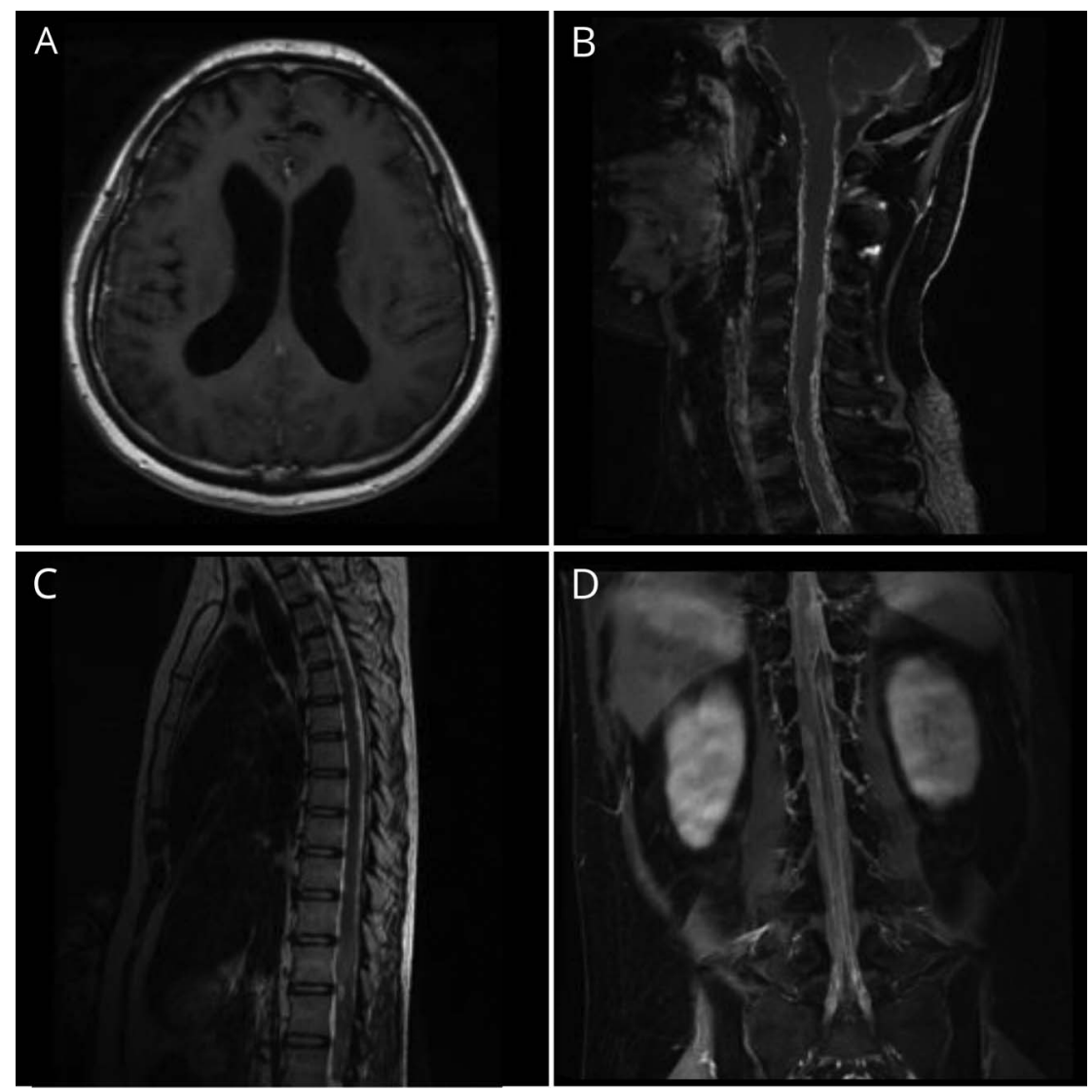

(A) T1-weighted brain MRI shows diffuse enhanced leptomeninges with ventriculomegaly. (B-D) T1weighted spinal cord MRI shows the spinal cord encased in diffuse thickened leptomeninges with enhancement. The lower segment of the thoracic spinal cord was swollen with slightly prolonged T1 and $\mathrm{T} 2$ signal. 


\section{Section 4}

Based on the symptoms, we inferred spinal cord involvement. Spinal MRI with gadolinium enhancement revealed striking diffuse thickened leptomeninges, coating the whole spinal cord, from the medulla oblongata to the cauda equina (figure 1, B-D). The lower segment of the thoracic spinal cord presented swelling with slightly prolonged $\mathrm{T} 1$ and $\mathrm{T} 2$ signals. Repeated lumbar puncture drained the xanthochromic and viscous CSF. The cell count was normal. The CSF protein level was higher than $5,000 \mathrm{mg} / \mathrm{dL}$. The glucose level decreased to $0.5 \mathrm{mmol} / \mathrm{L}$. The CSF cytology was still negative for malignancy. Meanwhile, we examined the ventricular CSF through the Ommaya reservoir; the protein level was $402 \mathrm{mg} / \mathrm{dL}$ and the glucose level $2.9 \mathrm{mmol} / \mathrm{L}$.

Due to treatment failure and CNS parenchyma involvement, we reconsidered meningeal carcinomatosis. To establish the final diagnosis, a meningeal biopsy was performed at the lower thoracic segment, and pathologic analysis revealed primary diffuse leptomeningeal gliomatosis, WHO grade II-III (probable pleomorphic xanthoastrocytoma; figure e-1, links.lww.com/WNL/A501). Chemotherapy was recommended, but the patient discharged himself and there was no follow-up.

\section{Discussion}

Primary diffuse leptomeningeal gliomatosis (PDLG) is characterized by diffuse infiltration of neoplastic glial cells in the leptomeninges, without evidence of a primary intraparenchymal tumor. ${ }^{1}$ PDLG is very rare; it tends to affect adults and a male predominance is observed. ${ }^{2,3}$ The proliferating neoplastic cells are more frequently of astrocytic origin. ${ }^{3}$ However, to our knowledge, pleomorphic xanthoastrocytoma presenting with PDLG has not been previously reported.

The neurologic symptoms of PDLG can mimic chronic meningitis or polyradiculopathy. ${ }^{2}$ Typically, patients present early with elevated intracranial pressure. Visual loss is presumably due to increased intracranial pressure or focal involvement of the optic nerves, and seizures may ensue. ${ }^{2}$ Imaging features include diffuse leptomeningeal contrast enhancement, spinal cord involvement, and ventriculomegaly. PDLG should have simple diffuse leptomeningeal involvement. However, some parenchymal involvement may appear, involving the superficial parenchyma or Virchow-Robin spaces. ${ }^{4}$

CSF cytology is essential for diagnosis of secondary leptomeningeal carcinomatosis. However, CSF examination infrequently detects malignant cells in PDLG. ${ }^{3}$ In one review on PDLG, cytologies were positive in 5 of 45 reported cases. ${ }^{5}$ Hypoglycorrhachia may occur in PDLG, and the CSF protein level is often high. ${ }^{2}$ Chloride concentration reduction is likely a response to elevated CSF protein level to maintain the osmotic pressure balance between CSF and plasma. Generally, high protein concentration in the CSF is nonspecific. However, a protein level of more than $5,000 \mathrm{mg} / \mathrm{dL}$ is very rare. The moderately elevated protein and slightly decreased glucose ventricular CSF levels suggested blockage of the spinal canal by thickened neoplastic leptomeninges and secretion of malignant cells.

The main differential diagnosis of PDLG is tuberculous meningitis. Treatment with antituberculous therapy is not uncommon. ${ }^{1,5}$ Optimally, the CSF specimens should be examined by acid-fast stain and culture to confirm tuberculous meningitis. A study involving 132 patients found that a bacteriologic diagnosis was achieved in $82 \%$ of cases; acidfast bacilli (AFB) smear and culture were positive in $58 \%$ and $71 \%$ of cases, respectively. ${ }^{6}$ In one series study, $37 \%$ of cases were diagnosed based on an initial AFB smear; the diagnostic yield increased to $87 \%$ when up to 4 serial specimens were examined, even if antituberculosis therapy had been initiated before a positive smear result was obtained. ${ }^{7}$ Nucleic acid amplification (NAA) tests appear to have high specificity but only moderate sensitivity, ${ }^{8}$ suggesting that negative NAA results cannot be used to exclude tuberculous meningitis.

The diagnosis of PDLG is challenging. The duration from onset to final diagnosis in this case was 33 weeks. Debono et al. ${ }^{9}$ proposed the following diagnostic criteria: (1) no apparent attachment of extramedullary meningeal tumor to the neural parenchyma; (2) no evidence of primary neoplasia within the neuraxis; (3) existence of distinct leptomeningeal encapsulation around the tumor. PDLG is usually diagnosed by meningeal biopsy or autopsy. There are no guidelines for therapy. A combination of temozolomide and radiotherapy may be beneficial, but the prognosis is poor, with a median survival of 4 months. ${ }^{5}$

We suggest that PDLG should be included in the differential diagnosis in cases of increased intracranial pressure with leptomeningeal involvement, especially when tuberculous meningitis is suspected and the patient is unresponsive to treatment. Surgical biopsy can be performed in patients where a precise etiology cannot be otherwise ascertained.

\section{Author contributions}

Dr. Jiang: clinical data review, literature review, writing of the first draft. Dr. Han and Dr. Fan: acquisition of data, intellectual contribution on clinical decision-making. Dr. Gao: performing meningeal biopsy, intellectual contribution. Dr. Cui: analyzing the data, intellectual contribution. Dr. Zhong: providing the final pathologic diagnosis, critical revision of the manuscript. Dr. Peng: critical revision of the manuscript for intellectual content, contribution on clinical decision-making. 


\section{Study funding}

No targeted funding reported.

\section{Disclosure}

The authors report no disclosures relevant to the manuscript. Go to Neurology.org/ $\mathrm{N}$ for full disclosures.

\section{References}

1. Ruiz-Ares G, Collantes-Bellido E, Rodriguez de Rivera F, et al. Primary diffuse leptomeningeal gliomatosis mimicking meningeal tuberculosis. Neurologist 2011;17:160-163.

2. Jicha GA, Glantz J, Clarke MJ, et al. Primary diffuse leptomeningeal gliomatosis. Eur Neurol 2009;62:16-22.
3. Tauziede-Espariat A, Maues de Paula A, Pages M, et al. Primary leptomeningeal gliomatosis in children and adults: a morphological and molecular comparative study with literature review. Neurosurgery 2016;78:343-352.

4. Cho HJ, Myung JK, Kim H, et al. Primary diffuse leptomeningeal glioneuronal tumors. Brain Tumor Pathol 2015;32:49-55.

5. Yomo S, Tada T, Hirayama S, et al. A case report and review of the literature. J Neurooncol 2007;81:209-216.

6. Thwaites GE, Chau TT, Farrar JJ. Improving the bacteriological diagnosis of tuberculous meningitis. J Clin Microbiol 2004;42:378-379.

7. Kennedy DH, Fallon RJ. Tuberculous meningitis. JAMA 1979;241:264-268.

8. Pai M, Flores LL, Pai N, et al. Diagnostic accuracy of nucleic acid amplification tests for tuberculous meningitis: a systematic review and meta-analysis. Lancet Infect Dis 2003;3:633-643.

9. Debono B, Derrey S, Rabehenoina C, et al. Primary diffuse multinodular leptomeningeal gliomatosis: case report and review of the literature. Surg Neurol 2006; $65: 273-282$.

\section{Disputes \& Debates: Rapid online correspondence}

The editors encourage comments on recent articles through Disputes \& Debates:

Access an article at Neurology.org/ $\mathrm{N}$ and click on "COMMENT" beneath the article header. Responses will be posted within 3 business days.

Before submitting a comment to Disputes \& Debates, remember the following:

- Disputes \& Debates is restricted to comments about studies published in Neurology within the last eight weeks

- Read previously posted comments; redundant comments will not be posted

- Your submission must be 200 words or less and have a maximum of five references; reference one must be the article on which you are commenting

- You can include a maximum of five authors (including yourself)

\section{Register for July Sports Concussion Conference in Indianapolis}

Secure your hotel and take advantage of early registration savings for the 2018 AAN Sports Concussion Conference this July 20 through 22 at the JW Marriott in Indianapolis, IN. The early registration deadline is June 14.

New this year:

- Joint programming with the NCAA including a Networking Reception at the NCAA Hall of Champions and talks focusing on the NCAA-DoD CARE Consortium

- Working Lunch with Experts who will address controversial issues in sports

- A Year in Review featuring the latest updates in concussion research and clinical guidance

- Unique and interactive "What Do I Do Now?" sessions where faculty will share challenging real-life cases and attendees will be invited to weigh in on best practices

Visit AAN.com/view/ConcussionConference 


\section{Neurology}

Clinical Reasoning: An 18-year-old man with progressive headache and visual loss Nan Jiang, Fei Han, Si-Yuan Fan, et al.

Neurology 2018;90;1076-1081

DOI 10.1212/WNL.0000000000005634

This information is current as of June 4, 2018

\section{Updated Information \& Services}

References

Subspecialty Collections

Permissions \& Licensing

Reprints including high resolution figures, can be found at: http://n.neurology.org/content/90/23/1076.full

This article cites 9 articles, 1 of which you can access for free at: http://n.neurology.org/content/90/23/1076.full\#ref-list-1

This article, along with others on similar topics, appears in the following collection(s):

Cerebrospinal Fluid

http://n.neurology.org/cgi/collection/cerebrospinal_fluid Meningitis

http://n.neurology.org/cgi/collection/meningitis

Primary brain tumor

http://n.neurology.org/cgi/collection/primary_brain_tumor

Information about reproducing this article in parts (figures,tables) or in its entirety can be found online at:

http://www.neurology.org/about/about_the_journal\#permissions

Information about ordering reprints can be found online:

http://n.neurology.org/subscribers/advertise

Neurology ${ }^{\circledR}$ is the official journal of the American Academy of Neurology. Published continuously since 1951, it is now a weekly with 48 issues per year. Copyright @ 2018 American Academy of Neurology. All rights reserved. Print ISSN: 0028-3878. Online ISSN: 1526-632X.

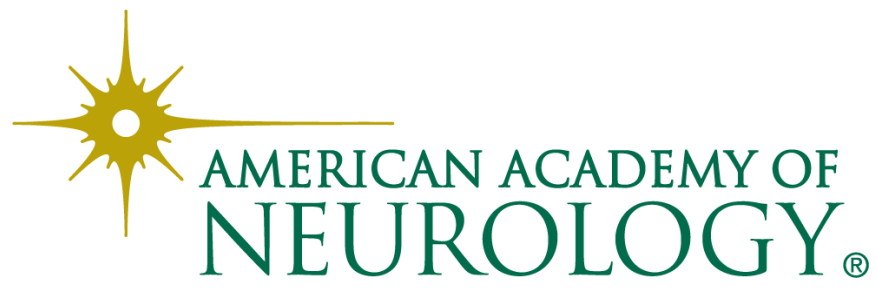

